\title{
Development of a HTSMA-Actuated Surge Control Rod for High-Temperature Turbomachinery Applications
}

\author{
Santo Padula, $\mathrm{II}^{1}$, Ronald Noebe ${ }^{1}$, Glen Bigelow ${ }^{1}$, Dennis Culley ${ }^{2}$, Mark Stevens ${ }^{3}$, Nicholas Penney ${ }^{4}$, \\ Darrell Gaydosh ${ }^{4}$ \\ NASA Glenn Research Center, 21000 Brookpark Rd., Cleveland, OH, 44135 \\ Todd Quackenbush ${ }^{5}$ \\ Continuum Dynamics, Inc., 34 Lexington Avenue, Ewing, NJ 08618 \\ and \\ Bernie Carpenter ${ }^{6}$ \\ B \& B Consulting, 9713 West Long Drive, Littleton, CO 80123
}

\begin{abstract}
In recent years, a demand for compact, lightweight, solid-state actuation systems has emerged, driven in part by the needs of the aeronautics industry. However, most actuation systems used in turbomachinery require not only elevated temperature but high-force capability. As a result, shape memory alloy (SMA) based systems have worked their way to the forefront of a short list of viable options to meet such a technological challenge. Most of the effort centered on shape memory systems to date has involved binary NiTi alloys but the working temperatures required in many aeronautics applications dictate significantly higher transformation temperatures than the binary systems can provide. Hence, a high temperature shape memory alloy (HTSMA) based on NiTiPdPt, having a transformation temperature near $300{ }^{\circ} \mathrm{C}$, was developed. Various thermo-mechanical processing schemes were utilized to further improve the dimensional stability of the alloy and it was later extruded/drawn into wire form to be more compatible with envisioned applications. Mechanical testing on the finished wire form showed reasonable work output capability with excellent dimensional stability. Subsequently, the wire form of the alloy was incorporated into a benchtop system, which was shown to provide the necessary stroke requirements of $\sim 0.125$ inches for the targeted surge-control application. Cycle times for the actuator were limited to $\sim 4$ seconds due to control and cooling constraints but this cycle time was determined to be adequate for the surge control application targeted as the primary requirement was initial actuation of a surge control rod, which could be completed in approximately one second.
\end{abstract}

${ }^{1}$ Materials Research Engineer, NASA GRC, MS 49-3, 21000 Brookpark Rd., Cleveland, OH, 44135.

${ }^{2}$ Control Systems Engineer, NASA GRC, MS 77-1, 21000 Brookpark Rd., Cleveland, OH, 44135.

${ }^{3}$ Mechanical Engineer, NASA GRC, MS 86-12, 21000 Brookpark Rd., Cleveland, OH, 44135.

${ }^{4}$ Senior Research Associate, OAI/NASA GRC, 21000 Brookpark Rd., Cleveland, OH, 44135.

${ }^{5}$ Senior Associate, Continuum Dynamics, Inc., 34 Lexington Avenue, Ewing, NJ 08618.

${ }^{6}$ Metallurgical Engineer, B \& B Consulting, 9713 West Long Drive, Littleton, CO 80123. 


\section{Introduction}

$\mathrm{V}$ ehicle systems of all types use, and are dramatically affected by, the actuation mechanisms they employ. Often these mechanisms are considered to be mission critical items, which under failure, can result in loss of life or capital equipment. This often drives the complexity and weight of an actuator and its supporting systems to extremes, thereby constraining vehicle designers to incremental improvements over long periods of time. In recent years, a new class of materials known as shape memory alloys has drawn substantial interest because of their potential to enable advanced, solid-state actuation mechanisms. The development of shape memory alloy actuators promises to increase capability while lowering overall weight, space and power consumption.

In aero-vehicles the use of compact, lower weight, more energy efficient actuators would yield dramatic improvements in system performance. Furthermore, not only would performance improve but an entirely new capability to implement advanced control technologies internal to the engine, generically known as flow control [1], would be enabled. To be practical, however, many flow control strategies will require embedded, point-of-use actuation that subjects the actuation system to environmental extremes and space constraints [1]. Such conditions not only warrant the use of compact actuation schemes but require the use of shape memory alloys having high temperature capability. Unfortunately, no materials having the necessary temperature capability for typical flow control strategies in gas turbine engines currently exist. Once this limitation is overcome, successful implementation of turbomachinery flow control will be possible and could yield smaller, lighter engines with positive impacts on efficiency, operability, noise, emissions, and safety.

With this in mind, the present work sought to (1) develop a HTSMA with reasonable properties (e.g., work output and dimensional stability) and a transition temperature on the order of $300{ }^{\circ} \mathrm{C}$ and (2) demonstrate the viability of this new alloy in a demonstration component. Previous work by Noebe et al. [2] showed that NiTiPt alloys with Pt additions of 20 at\% produced HTSMAs with the desired transformation temperatures. These alloys also showed appreciable work output characteristics, highly desirable for actuator applications. However, the high costs of Pt could hinder further development and acceptance of NiTiPt HTSMA based actuation systems, due to economic constraints. Alternate systems were therefore investigated and it was found that NiTiPd alloys produced similar results [3,4], but that higher Pd additions were needed to obtain comparable transformation temperatures. However, these ternary NiTiPd alloys exhibited some degradation of dimensional stability during thermal cycling. As a result, this work sought to substitute small amounts of Pt for Pd in order to produce a quaternary version of the baseline $\mathrm{Ni}_{19.5} \mathrm{Ti}_{50.5} \mathrm{Pd}_{30}$ alloy investigated by Bigelow [3] but having better dimensional stability. In doing so, the characteristics of the quaternary alloy could be directly compared to the baseline ternary to determine if the quaternary alloy produced any benefits, which would be useful for the "benchtop" surge control demonstration component.

Since a large number of envisioned applications lend themselves easily to linear actuation concepts, wire has become the form of choice for a large number of proposed actuation systems. Both of the alloys, a baseline $\mathrm{Ni}_{19.5} \mathrm{Ti}_{50.5} \mathrm{Pd}_{30}$ and derivative $\mathrm{Ni}_{19.5} \mathrm{Ti}_{50.5} \mathrm{Pd}_{25} \mathrm{Pt}_{5}$, were therefore further processed into wire form. A cursory study of the wire was then conducted to determine the usefulness of the SMA material as the backbone of an actual solid state device.

\section{Procedures}

\section{A. HTSMA Processing}

In order to assess the viability of utilizing HTSMAs in actuator applications, various forms of the material were required. Initially, extruded rod was produced and utilized for characterization of baseline mechanical properties as well as a starting material from which wire could later be drawn.

\section{Extruded Rod}

Cylindrical ingots of the $\mathrm{Ni}_{19.5} \mathrm{Ti}_{50.5} \mathrm{Pd}_{25} \mathrm{Pt}_{5}$ alloy, measuring $25.4 \mathrm{~mm}$ in diameter by $102 \mathrm{~mm}$ in length, were produced by vacuum induction melting high purity elemental constituents inside a graphite crucible. Subsequent to casting, the ingots were homogenized in vacuum at $1050{ }^{\circ} \mathrm{C}$ for $72 \mathrm{hrs}$. The ingots were placed inside a steel can which was evacuated and sealed to prepare it for extrusion. The "canned" ingots were then extruded at $900{ }^{\circ} \mathrm{C}$ and an area reduction ratio of 7:1. Mechanical test samples were subsequently machined from this extruded rod. 


\section{Wire}

To process wire, the $\mathrm{Ni}_{19.5} \mathrm{Ti}_{50.5} \mathrm{Pd}_{25} \mathrm{Pt}_{5}$ material was repeatedly hot extruded at $900{ }^{\circ} \mathrm{C}$ by Anomet. To prevent $\mathrm{Fe}$ contamination of the alloy, the extrusion can was removed after each extrusion run via pickling, with the shape memory alloy being placed into a new extrusion can subsequent to the next extrusion cycle. As a result of this repeated process, the ingot was reduced from an initial diameter of $25.4 \mathrm{~mm}$ to $2.2 \mathrm{~mm}$. This rod was then centerless ground to a final diameter of $1.5 \mathrm{~mm}$ to remove the majority of the corrosion products and surface damage incurred during the pickling process. The rod was then annealed at $600{ }^{\circ} \mathrm{C}$ for $30 \mathrm{~min}$ and subsequently cold drawn to a final diameter of $0.5 \mathrm{~mm}$ by Dynalloy.

\section{B. HTSMA Microstructural Characterization}

Once processed, samples were mounted in Bakelite in both the transverse and longitudinal directions and metallographically polished to reveal any microstructural features. Scanning Electron Microscopy (SEM) was performed to analyze the morphology of any particulates/phases found. Energy Dispersive Spectroscopy (EDS) was also performed on these particulates/phases in order to reveal the chemical makeup of these regions of the microstructure. Once obtained, these results were compared against SEM/EDS and Transmission Electron Microscopy (TEM) results obtained for ternary NiTiPd alloys [4] to identify the phases present.

\section{HTSMA Mechanical Characterization}

\section{Monotonic}

Monotonic characterization of the as-extruded rod was performed in a servohydraulic load frame equipped with a digital controller. Tests were conducted in strain control at a rate of $1 \times 10^{-4} \mathrm{~s}^{-1}$ using a $12.7 \mathrm{~mm}$ gage length contact extensometer equipped with $85 \mathrm{~mm}$ long alumina probes with a v-chisel edge. Direct couple induction heating was used to heat the specimens with temperatures measured via type $\mathrm{K}$ thermocouples which were directly welded to the specimens. Temperature gradients across the gage portion of the specimens were held to within $+/-0.5 \%$ of the target test temperature.

\section{Work Output}

Work characteristics for the extruded rod were determined by running constant load thermal cycle experiments. In these tests, the specimen was loaded in strain control at a rate of $1 \times 10^{-4} \mathrm{~s}^{-1}$ until the desired load level was achieved. Subsequent to reaching the desired load level, the controller was mode switched into load control and the desired load level was maintained. The specimen was then thermally cycled twice from room temperature to 100 ${ }^{\circ} \mathrm{C}$ above the austenite finish temperature $\left(\mathrm{A}_{\mathrm{f}}\right)$ using a heating rate of $30{ }^{\circ} \mathrm{C} /$ minute. Successive tests were performed on the same sample with the bias load incremented at the end of every two thermal cycles, thereby producing a series of increasing load biased experiments. Work output characteristics were ascertained by multiplying the resulting transformation strain during the martensite-to-austenite transformation on the second heating cycle by the constant stress applied during the cycle. This process was repeated for all bias intervals.

Work characteristics of the wire were determined using a dead load apparatus. In this method, a section of HTSMA wire was suspended between two steel cables, one anchored and one attached to a weight pan. The wire was electrically isolated from the rest of the system and was heated using resistive heating by controlling the current in the wire with a DC power supply. The power supply was controlled externally with a computer using dSpace/Matlab to control the current/time cycle (or heating cycle) and the total number of cycles. Certified weights were used to achieve the desired biased load levels. The strain-time response of the load biased wire was measured using a pair of laser displacement sensors, which were also interfaced with the computer system for automatic data acquisition.

\section{Training}

Thermomechanical processing, which shall be referred to as "training", was also performed on some of the bulk samples to modify the structure of the material prior to testing. This process involved loading the material until a stress of $393 \mathrm{MPa}$ was achieved, thermally cycling the material through the transformation under load for 10 cycles and subsequently removing the load. Standard load-bias experiments were then performed to compare the resulting behavior with the "un-trained" material.

\section{Design and Development of a HTSMA-Actuated Surge Control Rod}

The particular flow control application identified in this program was a surge-control rod for the centrifugal compressor of a T700 engine. Initial work at Glenn Research Center (GRC), inside a Compressor Component Test 
Rig, indicated that a small disturbance protruding into the flow path had the potential to delay stall and increase the operating envelope for an engine [1]. Subsequent integration into a highly modified T700 Turboshaft gas turbine engine test bed utilized pneumatic-actuated surge control rods. The pneumatic system was developed primarily with the intention of demonstrating the viability of the original surge control concept and not as the final solution for implementation in aircraft. Incorporation of all the necessary pneumatic lines would be impossible to do in a real engine given space limitations, not to mention power requirements for driving the system. Consequently, a HTSMA (described in the previous section) was developed as the motive force for actuation of surge-control rods, as an eventual replacement for the current pneumatic actuator but that could operate within current space and power limitations of an actual engine.

Creation of a compact actuator was of primary concern as this was dictated by the space limitations within the existing engine systems. Secondarily, the design also looked to incorporate a HTSMA wire bundle that could eventually be contained within a flexible conduit but still provide the necessary actuation characteristics. This was desired due to the need to route the 18 inches of SMA wire, required to produce the targeted 0.125 inches of stroke, around existing engine components. Given that the device was intended to operate via the heating and cooling of wires, a simple mechanical beam type linkage was utilized to translate the pulling motion of the wire assembly into a pushing action on the surge rod. After accounting for all of these constraints and design characteristics, a demonstration device was devised. This device consisted of a package containing the surge control rod and stroke translation mechanism which measured only 6.5 inches long by 2 inches in width. The device also contained 2 wires measuring 18 inches long, but this wire length could be substantially shortened by modifying the stroke translation mechanism. Actuation characteristics of this device utilizing the NiTiPdPt HTSMA wire are presented in section III.C.

\section{Results and Discussion}

\section{A. NiTiPdPt Characterization \& Transformation Temperatures}

It is useful to determine whether the SMA material is single phase as precipitates can rob the matrix of elemental constituents, which can have a deleterious effect on properties. As has been shown for binary NiTi [5,6,7] and NiTiPd [8], small shifts in stoichiometry toward the Ni-rich (Ti-lean) side can significantly lower the transformation temperature of the material. As such, the $\mathrm{Ni}_{19.5} \mathrm{Ti}_{50.5} \mathrm{Pd}_{25} \mathrm{Pt}_{5}$ alloy was initially processed with slightly Ti-rich starting composition. Figure 1 shows that small amounts (less than 4 vol\%) of second phase particles were observed. These second phase particles were determined to be $\mathrm{TiC}$ and $\mathrm{Ti}_{2}(\mathrm{Ni}, \mathrm{Pd}, \mathrm{Pt})$. The $\mathrm{TiC}$ particles were the result of the vacuum induction melting (VIM) process. This process utilized a graphite crucible, with approximately 0.4 at $\%$ of the carbon from the crucible dissolved in the melt resulting in small amounts of carbide particulate. As has been shown previously [2,3], the $\mathrm{Ti}_{2}(\mathrm{Ni}, \mathrm{X})$ phase is isostructural to $\mathrm{Ti}_{2} \mathrm{Ni}$ and is almost always observed in small quantities when the starting composition lies on the Ti-rich side of stoichiometry (i.e. $\mathrm{Ti}>50.0$ at $\%$ ).

Similar microstructures were seen in the wire (See Figure 2). However, the microstructure of the wire also showed small amounts of voids near the $\mathrm{Ti}_{2}(\mathrm{Ni}, \mathrm{Pd}, \mathrm{Pt})$ particles. These voids were attributed to the fracture of the $\mathrm{Ti}_{2}(\mathrm{Ni}, \mathrm{Pd}, \mathrm{Pt})$ during the cold drawing processes. The microstructure of the wire is similar to that observed for NiTiPt wire [9] where the microstructure (pores and cracked intermetallic phase) was responsible for a reduced fatigue life but did not seem to have any measurable effect on the basic load-biased strain-temperature response of the material. 


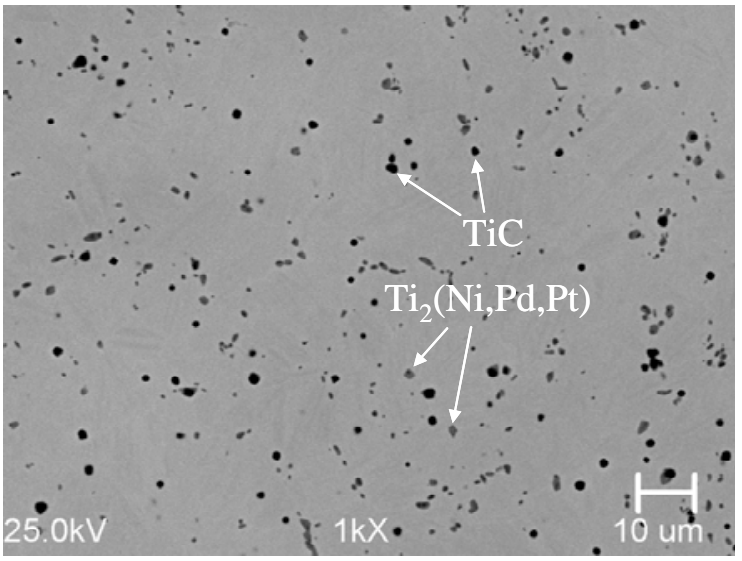

Figure 1. Microstructure of the bulk NiTiPd ${ }_{25} \mathbf{P t}_{5}$ alloy.

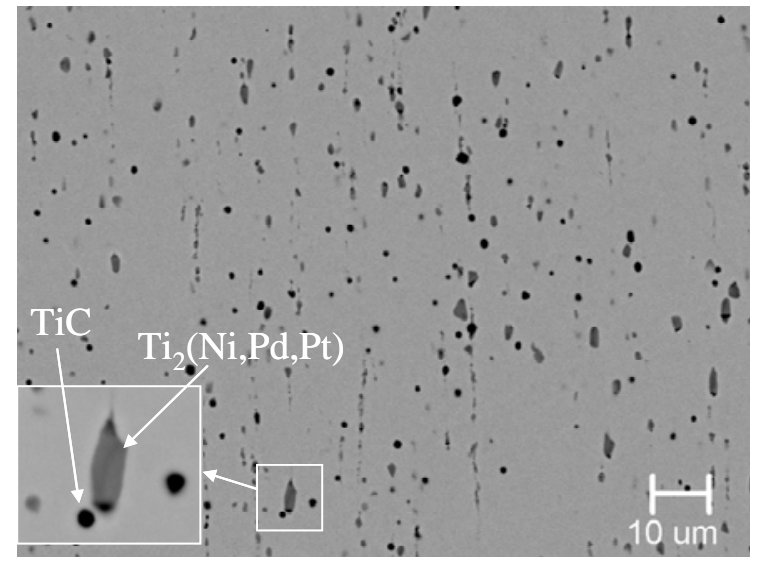

Figure 2. Microstructure of the NiTiPd ${ }_{25} \mathbf{P t}_{5}$ wire.

Because the resulting microstructures remained predominately single phase with matrix compositions on the Tirich side of stoichiometry, the extents of the transformation for $\mathrm{Ni}_{19.5} \mathrm{Ti}_{50.5} \mathrm{Pd}_{25} \mathrm{Pt}_{5}$, i.e. the temperature range over which the forward and reverse transformations occur, were observed to be between 228 and $259{ }^{\circ} \mathrm{C}$ (See Table 1 for more information regarding the important temperatures associated with the forward and reverse transformations). These transformation temperatures were almost identical to what was previously observed for the ternary $\mathrm{Ni}_{19.5} \mathrm{Ti}_{50.5} \mathrm{Pd}_{30}$ [4], as would be expected. Conventional binary NiTi alloys, however, transform at temperatures between 60 and $100{ }^{\circ} \mathrm{C}$, depending on the composition. Since ambient conditions within the turbomachinery are often times hotter than this, binary systems cannot be utilized as the system would already be in a state above the transformation and no shape recovery would occur as a result of further temperature increases. These alloys are therefore considered to be low temperature alloys as they cannot meet the challenges associated with higher ambient environments. However, the higher transition temperatures of the NiTiPd and NiTiPdPt alloys afford new possibilities for aeronautics applications. For areas of the turbomachinery where ambient temperatures are around $200{ }^{\circ} \mathrm{C}$ or lower, alloys like the NiTiPdPt can be effectively utilized. In such situations, the small temperature difference between the ambient condition and the beginning of the transformation makes the HTSMA even more desirable because lower amounts of power are needed, i.e. small amounts of current to resistively heat the material through the transformation, to induce the shape change and produce actuation. As such, actuation of the system being employed could be accomplished with significantly lower power requirements than is needed for traditional hydraulics or pneumatics, once an appropriate alloy is chosen for the application.

\section{B. Mechanical Properties of $\mathbf{N i}_{19.5} \mathbf{T i}_{50.5} \mathbf{P d}_{25} \mathbf{P t}$ \\ 1. Monotonic Behavior}

Monotonic tensile tests were conducted at a number of temperatures to determine the isothermal stress-strain response of the material both above and below the transformation. Although these characteristics were only ascertained for samples in the as-extruded form, the results did reveal some important observations with regard to relative strength differences. At temperatures below the martensite finish temperature $\left(\mathrm{M}_{\mathrm{f}}\right)$, the material is comprised of martensite variants. Deformation of the martensite phase produced the "de-twinning" response often observed in binary NiTi systems with the only exception being that the classic plateau was not observed. Instead, a hardening plateau was seen and this was attributed to the substitutional solid-solution strengthening which results from the precious metal additions. At the two higher temperatures shown in Figure $3\left(279\right.$ and $307^{\circ} \mathrm{C}$ ) the austenite phase is present and two distinctly different behaviors are observed. At the lower of these two temperatures, the material deforms by first stress-inducing martensite followed by plastic deformation of the remaining austenite. This occurs because the temperature is close to the austenite finish temperature $\left(\mathrm{A}_{\mathrm{f}}\right)$. At the higher temperature of $307^{\circ} \mathrm{C}$, the austenite phase is so stable that only plastic deformation of the austenite occurs. In any case, the strength of the austenite exceeds that of the martensite. This observation has been noted previously by Noebe et al. [2,10], Bigelow [3,4] and Padula et al. [11] for other HTSMA systems and has been determined to be a minimum (though not sufficient) requirement for alloys to exhibit good work output characteristics. This difference is important because of the underlying behavior that must be maintained during constant load, thermal cycling experiments (those used to determine work output capability), namely, the ability to create significant amounts of detwinning at a given load without inducing permanent deformation in the austenite phase once the material is heated through the 
transformation. Given the constitutive behavior presented in Figure 3, this is indeed the case and one should expect good work output characteristics from the NiTiPdPt alloy.

The monotonic tensile results of the quaternary system are compared to those of the baseline ternary $\mathrm{Ni}_{19.5} \mathrm{Ti}_{50.5} \mathrm{Pd}_{30}$ [4]. As can be seen in Figure 4, the small substitutional addition of Pt for Pd increased the resistance of the quaternary alloy to deformation over what was seen in the ternary system but probably had little effect on the amount of stress required to begin detwinning.

Table1. Transition temperatures for NiTiPd baseline ternary and NiTiPdPt quaternary alloys.

\begin{tabular}{|c|c|c|c|c|c|c|c|c|c|c|}
\hline \multicolumn{3}{|c|}{$\begin{array}{c}\text { Target Composition } \\
\text { (at\%) }\end{array}$} & $\begin{array}{c}\text { Extrusion } \\
\#\end{array}$ & \multicolumn{3}{c|}{$\begin{array}{c}\text { Transformation Temperature } \\
\left({ }^{\circ} \mathbf{C}\right)\end{array}$} & $\begin{array}{c}\text { Hysteresis } \\
\left({ }^{\circ} \mathbf{C}\right)\end{array}$ & $\begin{array}{c}\text { Transformation } \\
\text { Range } \\
\left({ }^{\circ} \mathbf{C}\right)\end{array}$ \\
\hline $\mathbf{N i}$ & $\mathbf{T i}$ & $\mathbf{P d}$ & $\mathbf{P t}$ & & $\mathbf{M}_{\mathbf{F}}$ & $\mathbf{M}_{\mathbf{S}}$ & $\mathbf{A}_{\mathbf{S}}$ & $\mathbf{A}_{\mathbf{F}}$ & $\mathbf{A}_{\mathbf{F}}-\mathbf{M}_{\mathbf{S}}$ & $\mathbf{A}_{\mathbf{F}}-\mathbf{M}_{\mathbf{F}}$ \\
\hline 19.5 & 50.5 & 30.0 & & 24 & 233 & 249 & 250 & 259 & 10 & 26 \\
\hline 19.5 & 50.5 & 25.0 & 5 & 48 & 228 & 247 & 243 & 259 & 12 & 31 \\
\hline
\end{tabular}

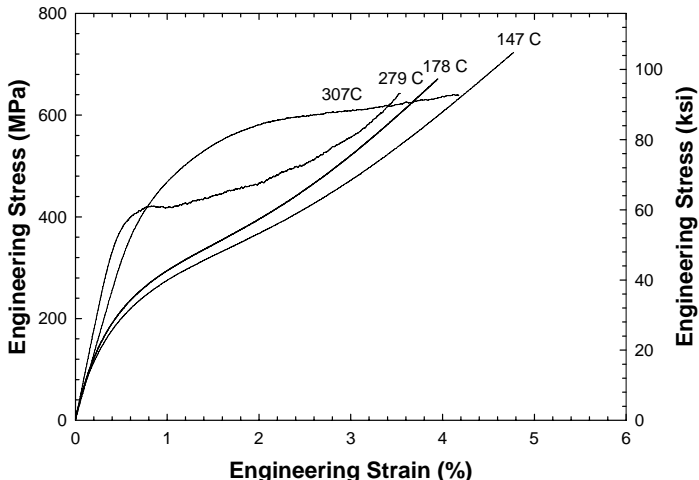

Figure 3. Monotonic response of $\mathrm{NiTiPd}_{25} \mathrm{Pt}_{5}$ at various temperatures.

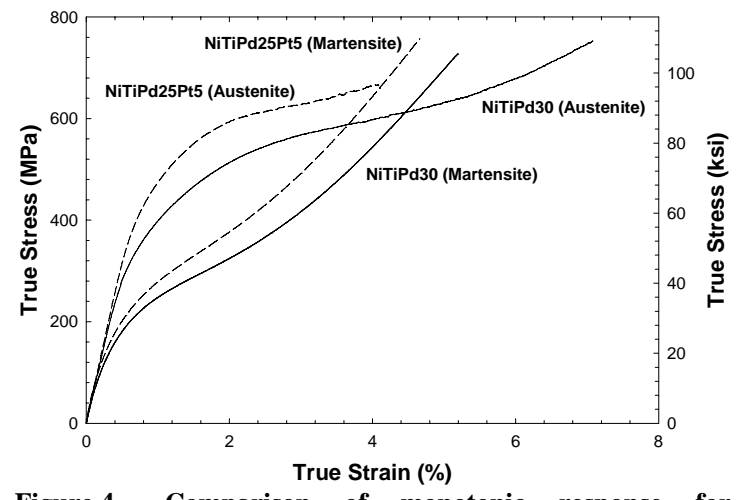

Figure 4. Comparison of monotonic response for NiTiPd $_{30}$ and NiTiPd $25 \mathrm{Pt}_{5}$, respectively.

\section{Work Output Behavior}

For a HTSMA to be useful as a solid state actuation component, the material must not only exhibit the shape memory effect at high temperature but must also be capable of restoring its shape in the presence of an externally applied load without undergoing significant plastic deformation. In other words, it must be capable of performing work against an externally applied force. The work potential of the $\mathrm{Ni}_{19.5} \mathrm{Ti}_{50.5} \mathrm{Pd}_{25} \mathrm{Pt}_{5}$ alloy was assessed by loadbias tests, where a constant load was applied to the material and the transformation strain was measured while the specimen was thermally cycled through the transformation. The resulting transformation strain was then multiplied by the applied stress to determine the work capability of the material. Since this work value is normalized, it can be compared directly to work values obtained in the same way on different forms of material, such as wire. Figure 6 shows the results of the load biased tests on the $\mathrm{Ni}_{19.5} \mathrm{Ti}_{50.5} \mathrm{Pd}_{25} \mathrm{Pt}_{5}$ at various stress levels. As can been seen in the figure, the alloy was capable of performing work at all levels of applied stress. The work output, however, was dependant on the amount of stress applied, increasing significantly with increasing stress level. This only stands to reason, since the amount of detwinning is directly dependant on the amount of applied load. Thus, the more detwinning that can be introduced into the structure without permanently deforming the martensite, the greater the amount of recoverable strain. This, then, translates directly into a greater amount of work output. 


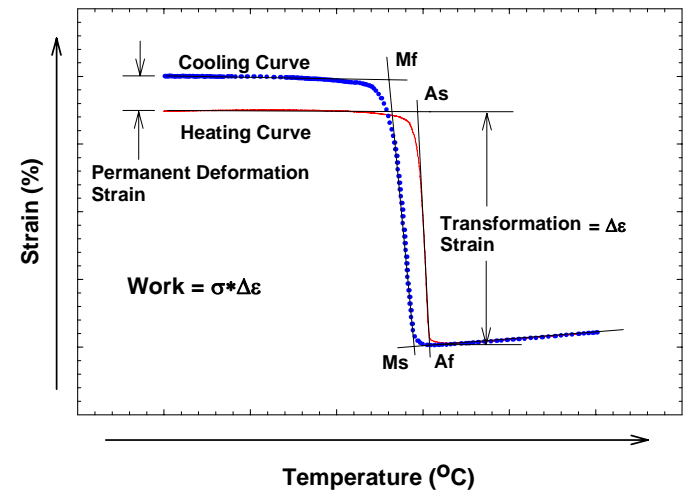

Figure 5. Methodology for determining properties from data obtained during a load-bias experiment.

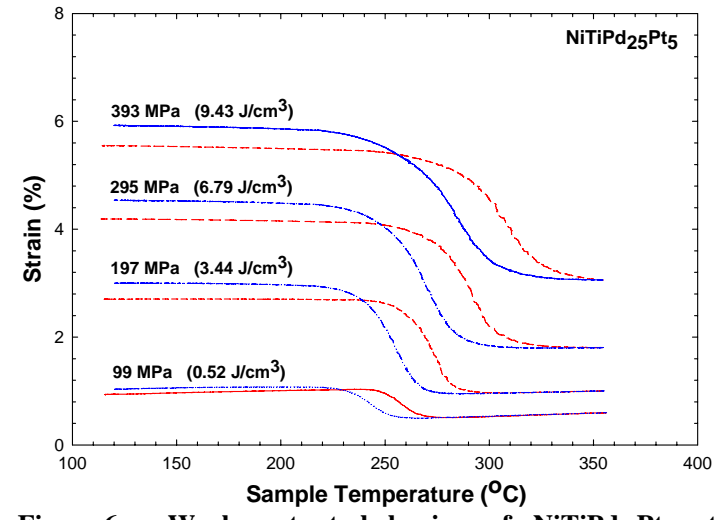

Figure 6. Work output behavior of $\mathrm{NiTiPd}_{25} \mathrm{Pt}_{5}$ at various applied stresses.

In comparing the $\mathrm{Ni}_{19.5} \mathrm{Ti}_{50.5} \mathrm{Pd}_{25} \mathrm{Pt}_{5}$ to the baseline ternary alloy, previously reported on by Bigelow [3,4], it can be seen that the amount of permanent deformation (See Figure 5 for a description of this quantity) that occurred during load-biased thermal cycling was reduced by a factor of 1.5 as a result of the alloying (See Figure 8 ). As was seen earlier, alloying with small amounts of Pt in place of Pd had the effect of strengthening both the martensite and the austenite against plastic deformation. From the results presented in Figure 8, this seems to be a plausible explanation for the reduction in permanent deformation strain observed. However, for the NiTiPdPt, it is still apparent that a greater strain results on cooling through the transformation than was present before heating (Figure 6 and 8) and that this strain is permanent since the loops do not close. This permanent deformation which remains in the NiTiPdPt after the completion of the thermal cycle was still deemed too high for device implementation. Since alloying with higher levels of Pt would inevitably defeat the purpose of keeping system costs low, other means of reducing this permanent deformation were investigated.

As was previously reported by Bigelow [4], thermomechanical processing has a significant impact on the amount of permanent strain accumulated during repeated thermal cycling under load. Samples of the Pt containing alloy were therefore "trained" in the same manner as has been reported for $\mathrm{NiTiPd}_{30}$ [4]. Figure 8 shows that training had a more substantial impact on the amount of permanent strain observed compared to alloying alone. After training, the main benefit of the Pt addition appears to be a slightly higher load capability.

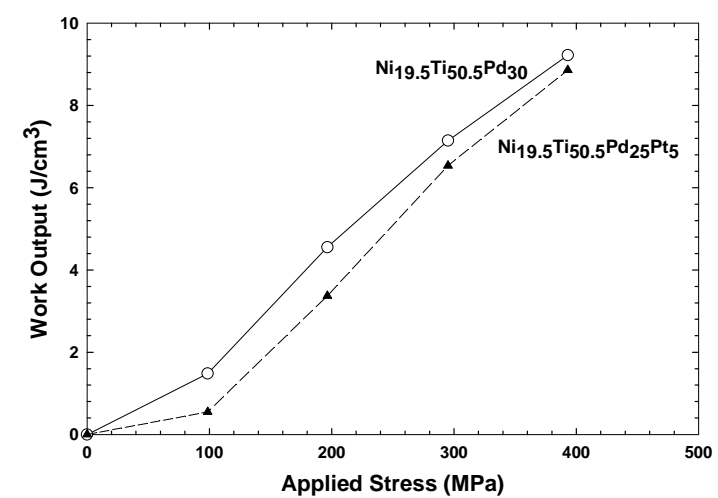

Figure 7. Effect of stress on the observed work output for the ternary and quaternary alloys.

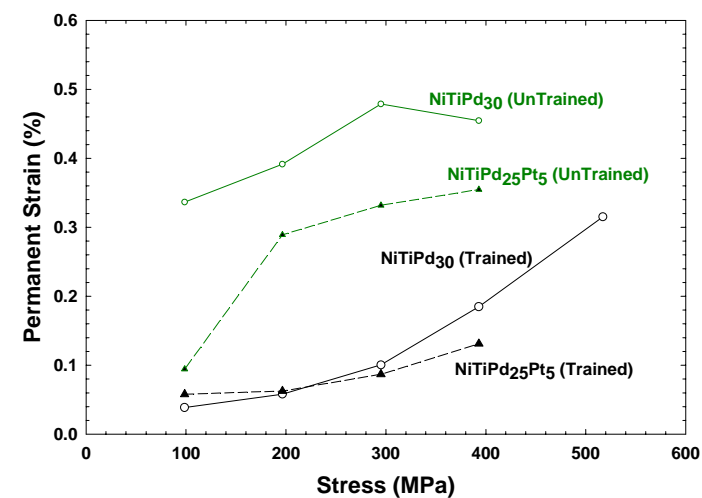

Figure 8. Effect of alloying and thermomechanical processing on permanent deformation during load-biased thermal cycling as a function of applied stress.

Because the differences in load-bias properties of the ternary and quaternary alloys were quite similar after "training", it was decided that both alloys would be processed into wire for possible use in the actuator. 


\section{Cyclic Properties of HTSMA Wire}

Multiple-extruded rods of both the ternary and quaternary alloys were processed into wire form by Dynalloy. The processing utilized cold drawing in conjunction with a proprietary technique that aimed to enhance the dimensional stability in a manner similar to the "training" that was used to refine the alloys shown in Figure 8. Mechanical testing was performed on the as-processed wire to determine if the dimensional stability sought was actually obtained. Figure 9 shows the results of performing load-biased thermal cycles on both the ternary baseline NiTiPd and quaternary NiTiPdPt wire at $173 \mathrm{MPa}(25 \mathrm{ksi})$. At first, it is surprising that the amount of plastic deformation observed in the wire form of the $\mathrm{Ni}_{19.5} \mathrm{Ti}_{50.5} \mathrm{Pd}_{30}$ alloy was far greater than what would be expected from the data obtained on bulk samples in the "trained" condition, while the plastic deformation observed in the $\mathrm{Ni}_{19.5} \mathrm{Ti}_{50.5} \mathrm{Pd}_{25} \mathrm{Pt}_{5}$ alloy wire was in good agreement with the bulk material.

Since the wire was only $0.5 \mathrm{~mm}$ diameter, it was extremely difficult to attach thermocouples to obtain accurate temperature measurements during thermal cycling. Therefore, preliminary experiments were conducted in an attempt to calibrate wire temperature with applied current. Subsequently, the maximum applied current was controlled in the expectation that an upper temperature of $350{ }^{\circ} \mathrm{C}$ would result. After seeing the large amount of plastic deformation in the $\mathrm{Ni}_{19.5} \mathrm{Ti}_{50.5} \mathrm{Pd}_{30}$ alloy, and knowing that the wire temperature was not directly measured, an alternate experiment was performed on bulk samples to see if slight amounts of overheating would explain the observed cyclic load-bias response in Figure 9. Figure 10 shows the results of tests whereby the samples were thermally cycled under load to various upper temperatures for 10 cycles. Once 10 cycles were completed at a given temperature, the upper temperature was incremented by $10{ }^{\circ} \mathrm{C}$ and the process was repeated with the accumulation of strain constantly monitored. As can be seen in the figure, both the NiTiPd and NiTiPdPt alloys have similar characteristics when the upper temperature was constrained to $350{ }^{\circ} \mathrm{C}$. However, once the upper temperature of the cycle nears $400{ }^{\circ} \mathrm{C}$, a remarkable difference in the behavior of the two alloys was observed with the NiTiPd exhibiting significant plastic deformation. This observation indicates that the benefit of $\mathrm{Pt}$ was greater than previously thought in that Pt also provides a significant amount of overtemperature protection to the material.

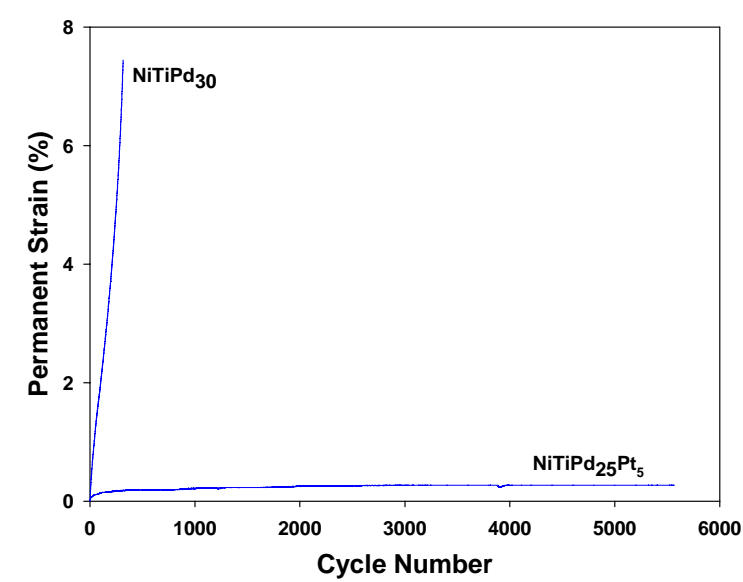

Figure 9. Durability of the ternary and quaternary alloys

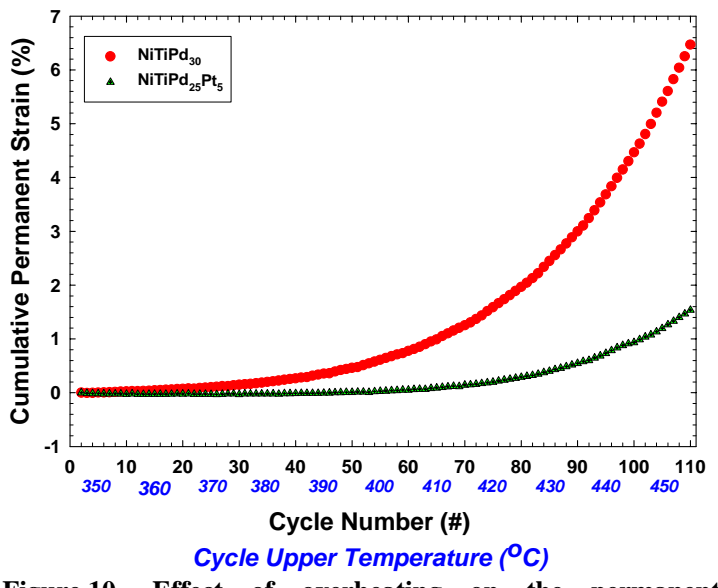

Figure 10. Effect of overheating on the permanent deformation displayed by the NiTiPd and NiTiPdPt.

As a result of the above lessons learned, the $\mathrm{Ni}_{19.5} \mathrm{Ti}_{50.5} \mathrm{Pd}_{25} \mathrm{Pt}_{5}$ alloy was selected as the material which provided the best overall properties needed for the envisioned application. Not only did the alloy exhibit good work output characteristics but the wire form also showed reasonable dimensional stability for lives exceeding 5000 cycles under conditions where overheating was likely to occur. The $\mathrm{Ni}_{19.5} \mathrm{Ti}_{50.5} \mathrm{Pd}_{25} \mathrm{Pt}_{5}$ was therefore incorporated into a demonstration surge control device for further evaluation.

\section{Benchtop Actuator Performance}

Once it was determined that the $\mathrm{Ni}_{19.5} \mathrm{Ti}_{50.5} \mathrm{Pd}_{25} \mathrm{Pt}_{5}$ was the most appropriate alloy to be used in the surge control actuator, two strands of the wire were incorporated into the demonstration actuator depicted in Figure 11. This device consisted of a surge control rod, HTSMA wire bundle, stroke translation mechanism and return spring. The idea behind this device was simple. When conditions at the onset of stall were sensed, a current could be applied to 
the HTSMA wire bundle causing the material to transform to austenite and contract. This contraction of the wire would then be converted into an extension of the surge control rod via the stroke translation mechanism. The extension of the surge control rod into the centrifugal compressor duct (i.e. the "deployed" position) causes a change in the flow characteristics of the engine, thereby mitigating the stall condition. Once the stall condition is averted, the applied current could be shut off allowing the HTSMA to cool. Under the restorative force of the return spring, the surge control rod tip would return to a position where it was flush with the compressor case, once the HTSMA had cooled below the $\mathrm{M}_{\mathrm{f}}$ temperature, thereby resetting the actuator should another stall condition warrant its use. In addition, the fail safe position for this actuator, if the wire or some other component were to fail, would be the unextended condition for this configuration, with the control rod flush with the case and out of the flow.

In order to improve the bandwidth of the device to reasonable levels, a complex control methodology for the resistive heating was employed. This methodology depended greatly on the amount of control voltage available. As can be seen in Figure 12, for lower control voltages (18 V), the response time of the surge control rod was extremely slow, taking 12-14 seconds to achieve full deployment. At higher control voltages, the methodology produced significantly better response times with deployment only requiring $\sim 1$ second (See Figure 13 for more detail). Also important to note is that the deployment times of the surge control rod where somewhat shorter than the retraction times on cooling. This occurs because the driving force for cooling (i.e. the temperature gradient) is constantly reduced as the temperature of the wire approaches the ambient temperature of the system. However, the "tailing" that is seen in Figures 12 and 13 on the cooling side of the cycle could be reduced by utilizing active cooling. In such a case, cycle times could be reduced by almost one second.

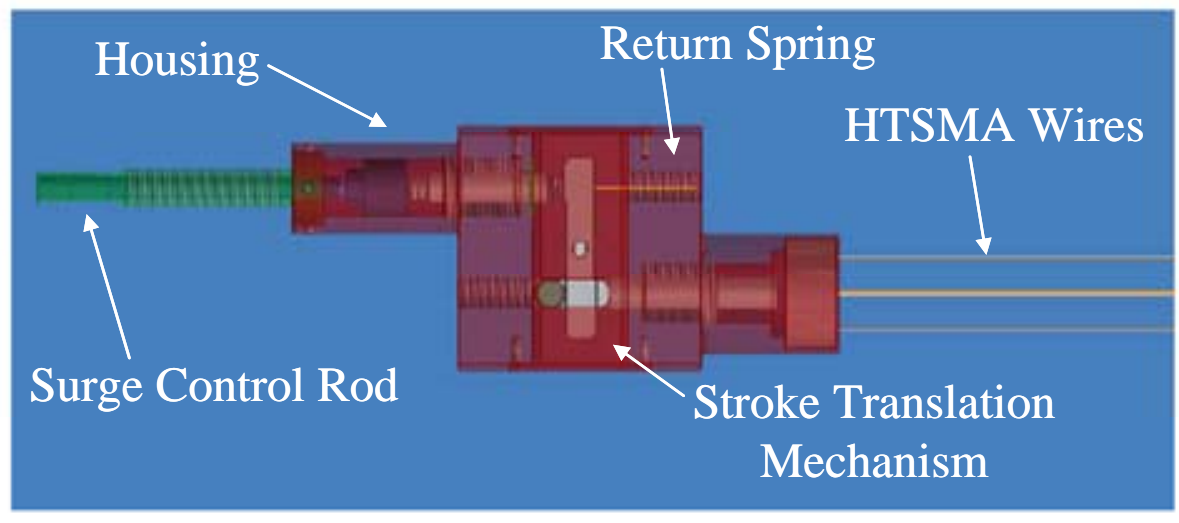

Figure 11. Depiction of the demonstration surge control device [12].

Position drift of the surge control rod was also seen on the deployment side of the response, most likely the result of temperature stabilization effects once the upper control current was established. Hence, control methodologies for obtaining accurate displacement control at relatively high bandwidths will most likely need to be complex and robust. Alternatively, actuator stroke was not an issue for the demonstration unit with the full 0.125 inches of stroke being easily met for all conditions attempted [12]. Thus, it appears that the largest impediment to successful utilization of HTSMA based systems will most likely come from either bandwidth or durability limitations. More research is required in both of these areas before it will be possible to truly determine the suitability of these actuators in commercial applications.

In this case, the demonstration device utilized 18 inches of wire to successfully extend the surge control rod the desired 0.125 inches. This wire length resulted from the desire to maintain the strain within the wire to $1 \%$ or less while utilizing a center pivot stroke translation mechanism (See Figure 11). In practice, this wire length could be substantially shortened by offsetting the pivot of the stroke translation mechanism. By moving the pivot closer to the wire side of the device, a smaller stroke due to the contraction of the wire would still translate into the 0.125 inches of stroke required for the surge control device. This benefit, however, would be offset by the need for the wire to be capable of producing more force as the resetting force induced by the return spring would be acting over a greater lever. This improved force capability can be achieved by either an increase in the number of wires used or by development of materials with improved properties. In the latter case, shortening of the wire lengths could provide other additional benefits related to power consumption. Assuming the number of wires remains fixed, a reduction in the wire length would provide lower power requirements than the $\sim 5$ watts needed to operate the demonstration unit, 
due to the lower overall resistance and volume of material needing to be transformed. This reduction in power consumption would make the SMA-based actuator even more attractive.

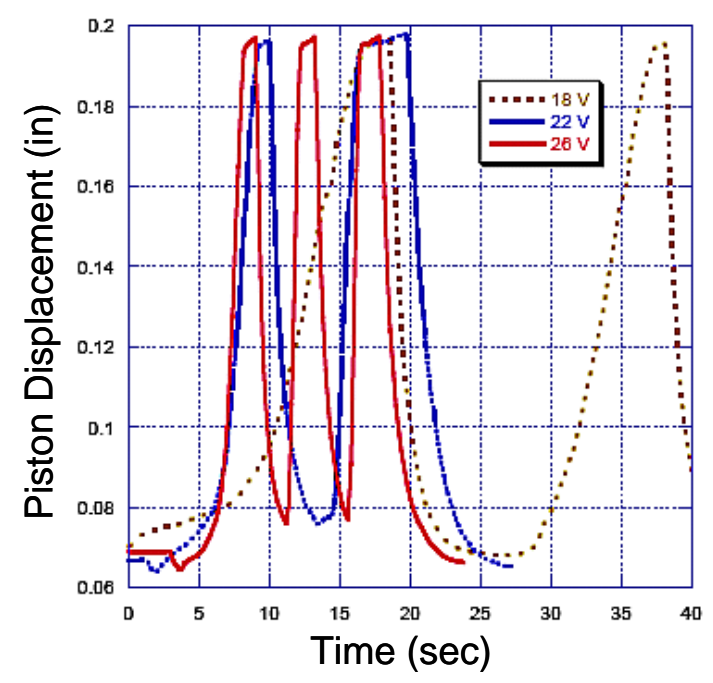

Figure 12. Demonstration actuator device performance as a function of applied external voltage [12].

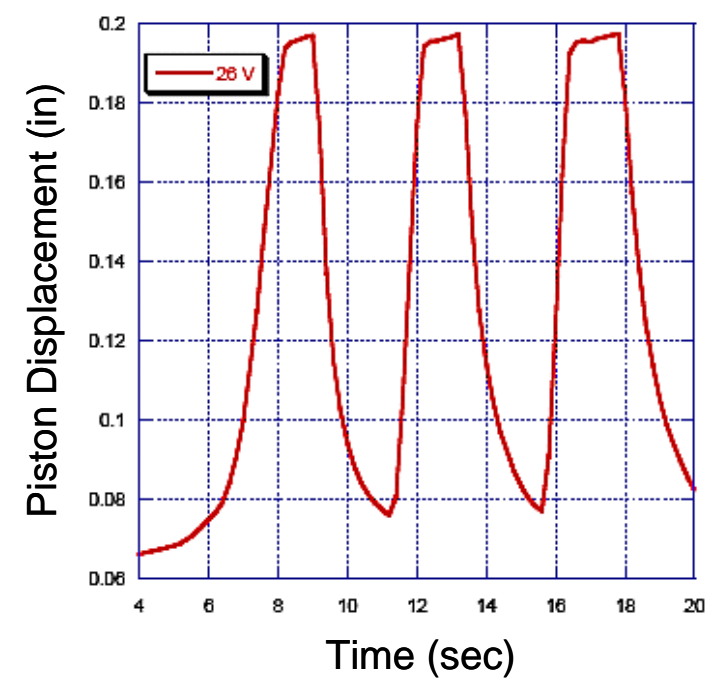

Figure 13. Expanded view showing details of the device response for $26 \mathrm{~V}$ condition [12].

\section{IV. “Lessons Learned” and Suggestions for a $2^{\text {nd }}$ Generation Actuator}

As an initial demonstration, the NiTiPdPt alloy developed in this work produced excellent results. Wire lengths necessary to produce the stroke requirements of the demonstration device could be reduced even further with the development of alloys producing greater recoverable transformation strains and work outputs. In order to achieve this goal, improving the material resistance to slip in both the martensite and austenite phases without significantly increasing the stress required for de-twinning is needed. This may be accomplished through further alloying to produce $3^{\text {rd }}$ generation materials.

In the case of real-world actuation, dimensional stability remains a critical component that must be fully understood prior to successful implementation. The permanent strain which occurs at the end of a cycle can be mitigated through a combination of alloying and thermomechanical processing. However, overheating can lead to creep and recovery which degrades or removes these previously gained benefits. As such, successful utilization of HTSMAs will require the designer to either account for these dimensional instabilities or know exactly how to inhibit their effect. More work focused on the mechanisms responsible for the observed reduction in permanent strain, as well as research focused at improving the recovery temperatures is therefore warranted.

In general, the amount of research focused at understanding fatigue and fracture of SMA systems is almost nonexistent. Before these materials can be effectively utilized in real-world applications, this area must be more fully understood as cyclic stresses often play a role in determining the life of components. Since these materials often exhibit brittle intermetallic phases which can be prime initiation sites for cracks, further work is needed to optimize the microstructure to eliminate or at least reduce the presence of these performance robbing attributes.

Advances in actuator design may also help to surmount some of the challenges associated with utilizing these unique materials in real world systems. Although it has been shown that wire systems can be utilized in designs where space constraints dictate compact actuators, alternate concepts and forms should be explored. Various design concepts for linear actuation systems are therefore being investigated in the hopes that alternate forms of the shape memory alloy can produce similar work characteristics and larger strokes while utilizing even more compact designs. One such concept utilizes stacks of sliding plates connected by SMA wire to produce enhanced stroke capability. At present, the authors of this work are contracting with the MIGA Motor Corporation to replace traditional binary NiTi SMA wire with the NiTiPdPt alloy presented here to develop a high temperature version of such a design. Many real world applications also employ spring-based designs which lend themselves to SMA-based alternatives. Currently, very little has been done to determine the capabilities of HTSMA springs but this form could produce distinct advantages especially in regards to further reductions in size requirements as well as antagonistic 
devices. All of these concepts pose their own unique challenges with years worth of effort needed to determine viability and usefulness, though several of these concepts have shown very encouraging preliminary results.

\section{Summary and Conclusions}

Although SMA materials have been around since the 1950's, very little has been done to extend these materials to elevated use temperatures. Until now, little work has focused at developing high temperature materials that are also capable of performing work against externally applied loads over many cycles. For the first time ever, a HTSMA capable of performing work was processed into a usable wire form and demonstrated in a solid state actuation system for an actual engine environment.

The quaternary $\mathrm{Ni}_{19.5} \mathrm{Ti}_{50.5} \mathrm{Pd}_{25} \mathrm{Pt}_{5}$ HTSMA showed the benefit of enhanced resistance to permanent deformation, especially under overtemperature type conditions, which warranted the utilization of the quaternary alloy in the device demonstration. This characteristic is vitally important to the successful utilization of real world actuators as such systems are often times controlled by means other than temperature monitoring. As such, overheating of the material is almost unavoidable and systems therefore need to be capable of operating under such constraints without inducing detrimental effects.

When incorporated in the demonstration component, the quaternary alloy showed good response characteristics. Deployment of the control rod was accomplished in $~ 1$ second which was determined to be fast enough for mitigating compressor stall. Cycle times were somewhat long, approaching 4 seconds, but other approaches such as active cooling may help further reduce this characteristic. Deployment position appeared to be somewhat unstable, most likely the result of non-uniform heating due to the complex control methodology employed. Further work must therefore be done in order to devise more robust control techniques.

In the end, the results have shown that successful utilization of HTSMAs is within reach. As such, HTSMAbased systems/actuators have an extremely important role to play in the development of adaptive hot-structures, with further investment in both materials research and actuator design warrented.

\section{Acknowledgments}

This work was supported by the NASA Glenn IR\&D fund and the Fundamental Aeronautics Program, Subsonic Fixed Wing Project.

\section{References}

\footnotetext{
${ }^{1}$ Skoch, G.J., "Experimental Investigation of Centrifugal Compressor Stabilization Techniques", Proceedings of ASME Turbo Expo 2003: Power for Land, Sea and Air, Atlanta, GA, June(2003).

2 Noebe, R. et al., "Properties and Potential of Two (Ni,Pt)Ti Alloys for Use as High-Temperature Actuator Materials,” Smart Structures and Materials 2005: Active Materials: Behavior and Mechanics, SPIE Conf. Proc. Vol. 5761, (2005), pp. 364-375.

${ }^{3}$ Bigelow, G., et al., "Development and Characterization of Improved High Temperature Shape Memory Alloys by Solid Solution Strengthening and Thermomechanical Processing of NiTiPd Alloys,” SMST 2006.

${ }^{4}$ Bigelow, G., "Effects of Palladium Content, Quaternary Alloying, and Thermo-Mechanical Processing on the Behavior of Ni-Ti-Pd Shape-Memory Alloys for Actuator Applications”, Master's Thesis, Colorado School of Mines, Golden, Colorado, 2006.

${ }^{5}$ Wasilewski R.J., Butler S.R., Hanlon J.E., and Worden D., "Homogeneity range and the martensitic transformation in TiNi”. Metall. Trans. 2:229, 1971.

${ }^{6}$ K. Otsuka and X Ren, "Physical metallurgy of Ti-Ni-based shape-memory alloys,” Prog. Maters. Sci. 50, 511-678 (2005).

${ }^{7}$ Melton, K.N., “Ni-Ti based shape memory alloys,” Engineering Aspects of Shape Memory Alloys, T.W. Duerig, K.N. Melton, D. Stöckel, and C.M. Wayman, eds., Butterworth-Heinemann, Ltd., Boston, MA, 1990, 21-35.

${ }^{8}$ Shimizu, S., Xu, Y., Okunishi, E., Tanaka, S., Otsuka, K. and Mitose, K., "Improvement of shape memory characteristics by precipitation-hardening of Ti-Pd-Ni alloys,” Maters. Lett. 34, 23-29, 1998.

${ }^{9}$ Noebe, R., et al., "Effect of Thermomechanical Processing on the Microstructure, Properties, and Work Behavior of a $\mathrm{Ti}_{50.5} \mathrm{Ni}_{49.5} \mathrm{Pt}_{20}$ High-Temperature Shape Memory Alloy”, SMST 2006.
} 
${ }^{10}$ Noebe, R. et al., "Properties of a $\mathrm{Ni}_{19.5} \mathrm{Pd}_{30} \mathrm{Ti}_{50.5}$ high-temperature shape memory alloy in tension and compression," Smart Structures and Materials 2006: Active Materials: Behavior and Mechanics, SPIE Conf. Proc. Vol. 6170, (2006).

${ }^{11}$ Padula II, S., et al., "Challenges and Progress in the Development of High-Temperature Shape Memory Alloys Based on NiTiX Compositions for High-Force Actuator Applications,” SMST 2006.

${ }^{12}$ Quackenbush, T. et al., NASA Contract NNC05QA61P, (2006). 